[ ensaio ]

\title{
A dois passos do deserto: visões urbanas de Euclides na Amazônia
}

\section{Milton Hatoum}

Resumo Através de algumas cartas de Euclides da Cunha tomamos conhecimento do seu olhar inquieto e urbano sobre a "emblemática" Amazônia. O fascínio e a aversão do escritor pela alteridade da região contribuem para uma escrita de tensão e miragem associada às impressões de modernidade, sugeridas pelas cidades de Belém e Manaus.

Abstract The reading of some Euclides da Cunha's letters discloses his restless and urban look on the "emblematic" Amazonian. His ambiguous feelings into this region, hesitating between enchantment and dislike, contribute to a strained and 'miragic' writing, that is tied to modernity impression from Belem and Manaus cities.

Palavras-chave cartas região Amazônica modernidade Keywords letters Amazonian region modernity 


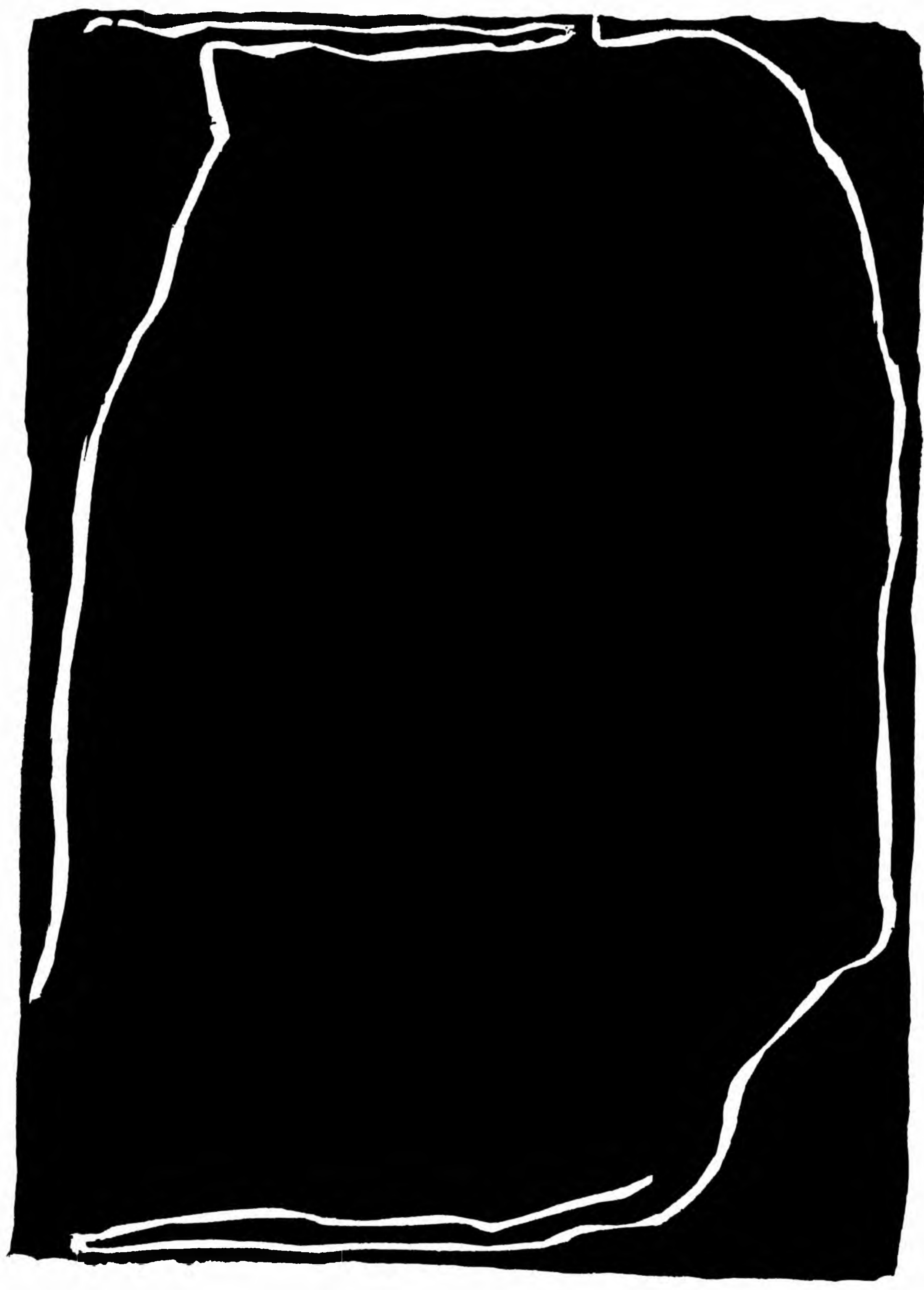


eu sinto necessidade de abandonar por algum tempo

o meio civilizado da nossa terra: assim ou aspiro os

sertões desertos ou as grandes capitais estrangeiras.

[Rio, 26.8.1892. Carta de Euclides da Cunha a Reinaldo Porchat|

Em várias cartas de sua extensa correspondência com amigos e parentes, Euclides exprime um desejo de movimento, de saída, de abandono do lugar: "não dou para a vida sedentária, tenho alguma coisa de árabe - já vivo a idealizar uma vida mais movimentada, numa comissão qualquer arriscada, aí por estes sertões desertos e vastos de nossa terra..."

Há, nessa inquietação interior, um desejo de evasão de si mesmo, de "liberdade de ser ou fazer-se diverso"2, de atração pela aventura e pelo risco, e ainda um forte desejo de conhecimento do outro. Euclides se enfada com a vida sedentária no "meio civilizado da nossa terra" e os seus projetos de partida apontam para lugares opostos o que há de mais civilizado ou de mais "inculto" (o deserto, lugar da barbárie, contra o qual Euclides "travou uma batalha obscura e trágica"3)

O lugar entre a metrópole e o deserto não parece exercer nenhum fascínio em Euclides. O que o seduz é a oposição extremada (civilização e barbárie) presente em muitos de seus escritos e que reflete "a consciência dividida presente no intelectual a um só tempo combativo e pessimista" 4 Dessa cisão resulta "o desenho da sua escrita literária de um modo que se abre para a tensão e a miragem"5

Cisão na consciência e cisão também na linguagem, que pende para o figu-

1 GALVÃO, Walnice Nogueira e GALOTTI, Oswaldo (org.). "Carta a Reinaldo Porchat. Rio, 26.8. 1892"

In: Correspondência de Euclides da Cunha. São Paulo: Edusp, 1997

2 HOLANDA, Lourival. "A letra e a lei" (texto inédito).

3 GALVÃO, Walnice Nogueira e GALOTTI, Oswaldo (org. ), op cit., "Carta a José Veríssimo. Manaus, 8.11.1905"

4 PRADO, Antonio Arnoni. "Ficção e verdade n'Os Sertões" Remate de males (Campinas: IEL, nº 13, p. 259, 1993).

5 Idem. 
ral e rompe com a moldura naturalista, tão presente à época de Euclides. A frase retorcida de seu estilo que tende a dramatizar tudo e em que "tudo parece impregnado de uma significação agônica" como bem assinalou Augusto Meyer6, não aparece apenas nas páginas de Os sertões, mas também em seus escritos amazônicos, inclusive nas cartas que escreveu em Manaus, antes de navegar para as cabeceiras do Purus.

Nessa correspondência Euclides também reflete, nas modulações de sua escrita, um movimento que alterna tensão e miragem a partir de uma vivência urbana. Perto do "deserto" ou cercado pela floresta, ele exalta o que há de mais civilizado e critica o que há de mais "primitivo" ou nativo nas capitais do Norte. Aqui, outra vez ele adere a uma visão extremada, em que não há lugar para um espaço urbano misturado. mestiço, formado por um urbanismo de terceiro estilo, conforme a expressão de Alejo Carpentier ao discorrer sobre La Habana, mas que bem se ajustaria à maioria das cidades latino-americanas.

Vem de longe o fascínio de Euclides pela Amazônia. Em carta a Luis Cruls, ele escreveu: "Alimento há dias o sonho de um passeio ao Acre"7 Mas já na segunda parte de Os sertões, numa breve digressão que ele chama "debuxos rápidos" ele discorre sobre as condições climáticas e mesológicas da Amazônia. Nessa e em outras passagens da obra de Euclides, comparece o que Gilberto Freyre nomeou de "descrença baseada em fatalismo de raça, em determinismo biológico" Descrença, portanto, "na incapacidade do mestiço: incapacidade biológica, fatal"8

A observação lúcida de Freyre, para quem Euclides é uma "vítima de preconceitos cientificistas com aparência de verdades antropológicas"9 encontra-se não apenas na famosa passagem citada pelo sociólogo, mas também nas páginas que sucedem aos "debuxos rápidos" sobre a Amazônia, mencionados antes. A descrença na incapacidade do mestiço e na do indígena - "a raça inferior, o selvagem bronco" - in-

6 "Nota sobre Euclides da Cunha" In: Textos críticos. São Paulo: Perspectiva, 1986, p. 242 7 GALVĀO, Walnice Nogueira e GALOTTI, Oswaldo (org.). op. cit., "Carta a Luis Cruls. Lorena, 20.2 1903" 8 FREYRE, Gilberto. Atualidade de Euclides da Cunha. Rio de Ianeiro: Casa do Estudante do Brasil, 1943. 9 Idem. 
fluiu na visão urbana de Euclides sobre as cidades da Amazônia. Ele demorou pouquíssimo tempo em Belém ("algumas horas inolvidáveis"). No entanto, a primeira e única impressão dessa cidade é reveladora:

(...) nunca esquecerei a surpresa que me causou aquela cidade. Nunca S. Paulo e Rio terão as suas avenidas monumentais largas de 40 metros e sombreadas de filas sucessivas de árvores enormes. Não se imagina no resto do Brasil, o que é a cidade de Belém, com os seus edifícios desmesurados, as suas praças incomparáveis e com a sua gente de hábitos europeus, cavalheira e generosa. Foi a maior surpresa de toda a viagem. ${ }^{10}$

Impressão forte e positiva (com ênfase pelo anafórico "Nunca") da urbs "modernizada" pelo senador Antônio Lemos, então intendente municipal da capital do Pará. Além da percepção do espaço urbano, que traduz uma visão idealizadora mas impactante de uma réplica de Paris em plena floresta, Euclides se impressiona "com a sua gente de hábitos europeus, cavalheira e generosa" Assim, a população harmoniza com a cidade, e ambas são promessas de uma possível civilização à entrada do deserto inculto.

Euclides viu Belém como quem vê de longe uma paisagem e se extasia. Não sentiu a pulsação da vida belenense, não caminhou pela Doca do Reduto e o Porto do Sal, não pôde observar detidamente o movimento do mercado Ver-o-Peso, onde as entranhas da cidade portuária se revelam. Passou ao largo desses lugares que mostram a complexidade da cidade e sua rede de relações com o interior da Amazônia. Ele viu a grandeza de Belém sob a perspectiva de amplas alamedas alinhadas por casarões e palacetes. Viu, enfim, a Belém do fausto da economia extrativista: visão impressionante que encerrava traços de uma promessa modernizadora ainda atual.

Ao desembarcar em Manaus, a surpresa foi de outra ordem e adquiriu um tom bastante diverso. Sua permanência nessa cidade, que deveria ter sido breve, prolongou-se por mais de três meses. No entanto, a espera permitiu um discernimento mais agudo sobre a vida urbana manauara. Trata-se de uma visão menos idealizada e

10 GALVÃO, Walnice Nogueira e GALOTTI, Oswaldo (org ), op. cit., "Carta ao pai. Manaus, 30.12 1904" 
muito mais crítica, apesar dos preconceitos à sociedade nativa. A vivência mais intensa permitiu-lhe captar certas contradições da cidade.

Nas cartas manauaras, a escrita de Euclides adquire um traço hiperbólico, eivado de tensão e de imagens contrastantes que lembram as melhores frases de sua prosa épica. O registro da vida urbana, feito de ângulos diferentes, é regido ao mesmo tempo por um fascínio e por uma aversão pela alteridade: fascínio pela "Hiloe portentosa" que envolve o escritor, e aversão por uma cidade que se lhe configura como o avesso de suas expectativas, de um ideal urbano que Belém emoldurara. É que em Manaus, a linguagem de Euclides exprime perplexidade e desenraizamento em face de um mundo preconcebido, preformado de leituras e visões que aos poucos ele questiona, reformula ou nega. A vivência em Manaus e a proximidade da floresta amazônica lhe causam uma estranheza que se reflete na linguagem, como se esta fosse o lugar mimético do exílio, "lugar da inversão de valores, da barbárie, da incultura" "1

Quanta coisa a dizer! - o desapontamento que me causou o Amazonas, menos que o Amazonas que eu trazia na imaginação; a estranha tristeza que nos causa esta terra amplíssima, maravilhosa e chata, sem um relevo onde o olhar descanse; e, principalmente, o tumulto, a desordem indescritível, a grande vida à gandaia dos que a habitam... Estou numa verdadeira sobrecarga de impressões todas novas, todas vivíssimas e empolgantes. Preciso de uma situação de equilíbrio para o espírito. ${ }^{12}$

Em Manaus ele vai exprimir o embate interno decorrente da atração pela diferença'3, da dificuldade de repensar um mundo prefigurado. O tumulto e a desordem (da cidade, do outro) expressam também o tumulto interior de um escritor cindido. E a desordem interna (a falta de um equilíbrio para o espírito) contraria, por meio da linguagem, o credo naturalista e o código positivista.

Em Manaus Euclides problematiza tudo. O autor de tantas cartas foi tam-

11 VENTURA, Roberto. "Euclides da Cunha" Remate de males, op. cit.

12 GALVÃO, Walnice Nogueira e GALOTTI, Oswaldo (org ), op. cit., "Carta a Oliveira Lima. Manaus, $161.1905^{\prime \prime}$

13 HOLANDA, Lourival, op cit 
bém o comentador contumaz de uma região brasileira que ele sabia periférica e desconhecida por seus conterrâneos. Daí o desejo, o empenho de ver o país por outro prisma, mesmo se essa visão às vezes é refratária ou míope.

Como não pensar em Mário de Andrade quando Euclides, em carta a Afonso Arinos, escreveu:

(...) a mais consoladora surpresa do sulista está no perceber que este nosso Brasil é verdadeiramente grande porque ainda chega até cá. Realmente, cada vez mais me convenço que esta deplorável rua do Ouvidor é o pior prisma por onde toda a gente vê a nossa terra ${ }^{14}$

O clima, a cidade, a região e, em parte, os homens que as habitam se thes apresentam como questões latentes e antecipam as reflexões mais percucientes reunidas nos ensaios de À margem da história.

Logo nas primeiras cartas, seus comentários sobre o "singularíssimo clima da Amazônia" 15 fazem eco às "pirexias estonteantes" e às "canículas abrasadoras" mencionadas n'Os sertões. Tomado por um estado febril constante, por uma espécie de sonolência mórbida, Euclides investe contra o clima equatorial. A frase "Eu escrevo-te doente" na carta enviada a Afonso Arinos 16, ainda revela a dificuldade de uma adaptação climática. No entanto, menos de uma semana depois, ele lança mão de uma metáfora para afirmar sua adaptação ou assimilação à diferença:

Eu, firme na minha envergadura esmirrada e seca, faço neste clima canicular prodígios de salamandra. Vou bem. Nem o mais ligeiro abalo, agora. Fiz as pazes com o sol do Equador e adapto-me admiravelmente na atmosfera úmida e quente, feita para as fibras das palmeiras e os nervos dos poetas. ${ }^{17}$

14 GALVÃO. Walnice Nogueira e GALOTTI, Oswaldo (org.), op. cit., "Carta a Afonso Arinos. Manaus, $12.1 .1905 "$

15 CUNHA, Euclides da. Os sertões. Ed. crítica de Walnice Nogueira Galvão. São Paulo: Ática, 1998. 16 GALVÃO, Walnice Nogueira e GALOTTI, Oswaldo (org.). op. cit., "Carta a Afonso Arinos. Manaus, 12.1.1905"

17 Idem. "Carta a Reinaldo Porchat. Manaus, 18. 1. 1905" 
Além das aliterações e do jogo fonético que dão plasticidade às linhas que iniciam e terminam esse trecho, são notáveis a metáfora da salamandra e a correspondência do clima à flora da região e ao estado poético. A metamorfose, implícita nos "prodígios de salamandra" bem pode ser lida como fruto de um processo de assimilação ou compreensão de uma outra cultura, ligado, com laivo romântico, ao fazer poético.

Aos poucos, esses prodígios vão apreendendo muita coisa da realidade urbana e regional. A crítica que ele teceu à cidade traduz não apenas o impasse de um urbanismo transplantado, mas também a fisionomia compósita e problemática da urbs. com sua face grotesca e dilacerada.

(...) caí na vulgaridade de uma grande cidade estritamente comercial de aviadores solertes, zangões vertiginosos e ingleses de sapatos brancos. Comercial e insuportável. O crescimento abrupto levantou-se de chofre fazendo que trouxesse, aqui, ali, salteadamente entre as roupagens civilizadoras, os restos das tangas esfiapadas dos tapuias. Cidade meio caipira, meio européia, onde o tejupar se achata ao lado de palácios e o cosmopolitismo exagerado põe ao lado do ianque espigado... o seringueiro achamboado, a impressão que ela nos incute é a de uma maloca transformada em Gand. 18

Euclides percebeu a modernidade manca, incompleta de Manaus, cujo crescimento abrupto, ocorrido durante a administração do governador Eduardo Ribeiro (1892-1896), contrasta com o de Belém. Esta seria "o sonho utópico ou a utopia sonhada" 19 de um espaço urbano na região equatorial. O crescimento de Belém foi pontuado por um processo de continuidade, pois sua urbanização avançara nas últimas décadas do século xvIII, e desde então se tornara uma cidade cêntrica ${ }^{20}$ Basta lembrar as igrejas e palácios governamentais projetados pelo arquiteto italiano Giuseppe Landi na segunda metade do século XVIII, quando Belém já havia causado uma forte impressão a viajantes e naturalistas estrangeiros.

Durante o período de 1880 a 1912, Belém foi o maior centro exportador do

18 Idem, "Carta a Domício da Gama. Manaus, 1905"

19 NUNES, Benedito. "Pará, capital Belém" (texto inédito).

20 Idem. 
látex, concentrando as atividades comerciais e financeiras de uma matéria-prima que chegou a representar $40 \%$ da exportação brasileira. Sua malha urbana foi ampliada e dotada dos mais sofisticados equipamentos de infra-estrutura. Além disso, as praças e palacetes em estilo art-nouveau, o Bosque Rodrigues Alves, e o Teatro da Paz (foco irradiador de uma atividade cultural intensa) davam a Belém uma aura de modernidade comparável a poucas cidades brasileiras. De certa forma, Mário de Andrade reiterou a impressão de Euclides: "Belém me entusiasma cada vez mais (...) foi feita pra mim e caibo nela que nem mão dentro de luva"21

Manaus, entretanto, era apenas um povoado acanhado antes do período extrativista. No pequeno núcleo portuário de $10 \mathrm{mil}$ habitantes, desprovido de traçado urbanístico, prevaleciam habitações rústicas de madeira e palha (materiais da arquitetura nativa) que se avizinhavam do casario não menos rústico de alvenaria e telha. A nova cidade, construída na última década do século xIx, não suprimiu as características de um povoado em que "os resíduos de costumes e atividades do índio eram um fato na movimentação da vida urbana"22 Daí o seu aspecto híbrido ("meio caipira, meio européia") mencionado por Euclides.

O "tejupar que se achata ao lado de palácios"23, ou a "maloca transformada em Gand" não são comparações de mero efeito retórico. Euclides intuiu o que ainda hoje é perceptível quando se compara Manaus com Belém. As diferenças entre ambas têm raízes fundas no processo histórico da colonização da Amazônia, com suas implicações sociais, culturais e econômicas.

A "Meca tumultuária dos seringueiros"24 e os "restos das tangas esfiapadas dos tapuias" dizem muito sobre a transformação social de uma cidade onde ainda moravam muitas famílias indígenas (inclusive tapuias) e onde também milhares de nordestinos dormiam em acampamentos, à espera de um barco que os transportasse aos

21 ANDRADE, Mário de. O turista aprendiz. São Paulo. Duas Cidades, 1983.

22 AB'SABER, Aziz. "A cidade de Manaus" Boletim Paulista de Geografia, no 15, 1953.

23 GALVÃO, Walnice Nogueira e GALOTTI, Oswaldo (org.), op. cit., "Carta a Domício da Gama. Manaus, 1905"

24 Idem. "Carta a José Veríssimo. Manaus, 13.1. 1905" 
seringais da Amazônia. A opulência da "cidade estritamente comercial" e "excessivamente cosmopolita" com seus "aviadores solertes, zangões vertiginosos e ingleses de sapatos brancos" não dissimulava as contradições sociais. Daí "as roupagens civilizadoras" dessa grande vitrine da modernidade, a que Euclides contrapõe "o seringueiro achamboado" e a "maloca transformada em Gand" 25

O que em Belém era miragem ou utopia sonhada, em Manaus torna-se tensão. Até mesmo no nome da cidade, Euclides vê uma "onomatopéia complicada e sinistra nesta palavra - feita do soar melancólico dos barés e da tristeza invencível do Bárbaro" Ele parece possuído ou contaminado cada vez mais por essa melancolia, "meu tédio lúgubre de Manaus" como revela em carta a Coelho Neto. Nessa carta, é significativa a passagem em que a cidade, "rasgada em avenidas, largas e longas, (...) faz-me o efeito de um quartinho estreito. Vivo sem luz, meio apagado e num estonteamento"26.

Esse movimento interior, que oscila do tédio a uma quase anulação de si, pode ser sintoma de sua estruturação psíquica, de uma momentânea inquietação interior. Mas o fato é que o tempo de espera em Manaus torna-se um suplício. Tempo longo demais numa cidade "desmandadíssima" que contraria seu ideal positivista, em que o progresso, associado à ordem, "exigia dos mais esclarecidos, dos luminares, no topo da sociedade, assistência aos desvalidos e higiene para melhorar a saúde e evitar as epidemias" 27

A "parada forçada e inaturável" em Manaus talvez tenha sido para ele uma punição de Tântalos, sempre ameaçado por uma grande pedra suspensa sobre sua cabeça, ameaçando esmagá-lo, impedindo-o de saborear um banquete à sua frente. Para Euclides, o banquete é o deserto, a viagem às cabeceiras do Purus. Enquanto espera o conserto das lanchas peruanas, ele anseia pela viagem várias vezes adiada. As cartas são pontuadas por essa ânsia de partir: "Estou a dois passos do deserto" ; "an-

25 Idem. "Carta a Domício da Gama, Manaus, 1905" Sobre o cotidiano dos pobres e excluídos da Manaus do ciclo da borracha, ver: A llusão do fausto, de Ednéa Mascarenhas Dias. Manaus: Ed. Valer, 1999. 26 GALVÃO, Walnice Nogueira e GALOTTI, Oswaldo lorg. I, op. cit., "Carta a Coelho Neto. Manaus. 10.3.1905" op. cit

27 NUNES, Benedito. op. cit 
sioso por me encontrar frente a frente com o deserto"; "estaquei à entrada do meu misterioso deserto do Purus"28. A grande cidade "insuportável" asfixia-o, causa-Ihe o efeito de um espaço diminuto e fechado (um quartinho estreito), enquanto o deserto já faz parte de sua viagem imaginária.

Há uma perspectiva de redenção e heroísmo nessa viagem: "o meu deserto bravio e salvador onde pretendo entrar com os arremessos britânicos de um Livingstone" O deserto, ou o "Desconhecido" como ele o nomeia três vezes, é um espaço também temerário, onde ele pode se perder e de onde a volta é uma dúvida: "Talvez, não volte. Falo, portanto, como quem se confessa." Mas o sentimento de apropriação e posse ("meu deserto") revela o empenho de compreender uma região desconhecida, e de "vingar-se" de impressões e comentários equivocados sobre uma "paragem onde Humboldt aventurou as suas profecias e onde Agassiz cometeu os seus maiores erros" 29

Nada te direi da terra e da gente. Depois, aí, e num livro: Um paraíso perdido, onde procurarei vingar a Hiloe maravilhosa de todas as brutalidades das gentes adoidadas que a maculam desde o século XVIII. Que tarefa e que ideal! 30

Euclides, confessadamente pessimista, apenas teve tempo de esboçar seu paraíso perdido. Diante de um mundo tão vasto e complexo, ele percebeu que estava diante de um grande desafio, senão de um impasse

É uma grandeza que exige a penetração sutil dos microscópios e a visão apertadinha e breve dos analistas: é um infinito que deve ser dosado( ...) Escreverei Um paraíso perdido, por exemplo, ou qualquer outro em cuja amplitude eu me forre de uma definição positiva dos aspectos de uma terra que, para ser bem compreendida, requer o trato permanente de uma vida inteira. ${ }^{31}$

28 GALVÃO, Walnice Nogueira e GALOTTI, Oswaldo (org.), op. cit., "Carta a Domício da Gama. Manaus, 1905" e "Carta a Dr. Edgard Jordão. Manaus, 22.1.1905"

29 Idem, trechos dispersos nas cartas: "Carta a Artur Lemos. Manaus, 1905" "Carta a Edgard Iordão Manaus, 22.1.1905" "Carta a Coelho Neto, Manaus. 10.3.1905" "Carta a Artur Lemos. Manaus, 1905"

30 Idem, "Carta a Coelho Neto. Manaus, 10.3.1905"

31 Idem, "Carta a Artur Lemos. Manaus, 1905" 
"Um infinito que deve ser dosado"32 é uma formulação (ou fórmula de abertura) que Euclides repetirá, com outras palavras, no ensaio inaugural do livro À margem da história. As linhas de força de suas idéias sobre a Amazônia já se revelam nesses três meses de permanência em Manaus. Ele não abandonou a busca de certezas ou verdades cientificistas; mas essa busca muitas vezes contorce a linha reta do escritorengenheiro, cuja linguagem conflui para verdades que "desfecham em hipérboles" e se enredam em lances de fantasia33

As cartas, em seu conjunto, testemunham as várias faces de um escritor confessadamente pessimista e atormentado, movido por um desejo tenaz de refletir e escrever sobre uma região emblemática, quase sempre vista por um olhar exótico. Mas o olhar de Euclides sobre as duas grandes cidades da Amazônia está longe de ser turvo ou ingênuo. Em Manaus ainda hoje se encontram, de uma forma muito mais ostensiva, os restos da sociedade nativa entre "as roupagens civilizadoras" 34

Milton Hatoum é professor de literatura da Universidade Federal do Amazonas e autor dos romances Relato de um certo Oriente [Cia. das Letras 1989] e Dois irmãos [a ser publicado em junho de 2000 pela Cia. das Letras].

32 Idem.

33 "Parece que ali a impotência dos problemas implica o discurso vagaroso das análises: às induções avantajam-se demasiado os lances da fantasia. As verdades desfecham em hipérboles. Ver "Impressões gerais" em À Margem da história. 2a ed. Porto: Livraria Chardron, Lelo E Irmão Editores, 1913.

$34 \mathrm{Cf}$. nota 18 deste ensaio. 